\title{
Improvement of Mechanical Properties of Anisotropic Glassy Polystyrene by Introducing Heat-Labile Reversible Bonds
}

\author{
Wendi Wang, ${ }^{(0)}$ Jeppe Madsen,* Anne L. Skov, ${ }^{\circledR}$ and Qian Huang*(i) \\ Department of Chemical and Biomedical Engineering, Technical University of Denmark, 2800 Kgs. Lyngby, Denmark
}

Supporting Information

ABSTRACT: Carboxylic acid groups were introduced into polystyrene, and the effect both on melt rheology and on mechanical properties of stretched and quenched anisotropic solids below the glass-transition temperature $\left(T_{\mathrm{g}}\right)$ was investigated. First, the facile preparation of well-defined copolymers of styrene (S) and 4-vinylbenzoic acid (A) by reversible addition-fragmentation chain-transfer polymerization was demonstrated. The evaluation of monomer reactivity ratios shows that the acid polymerizes faster than styrene but shows that block formation is suppressed under the applied
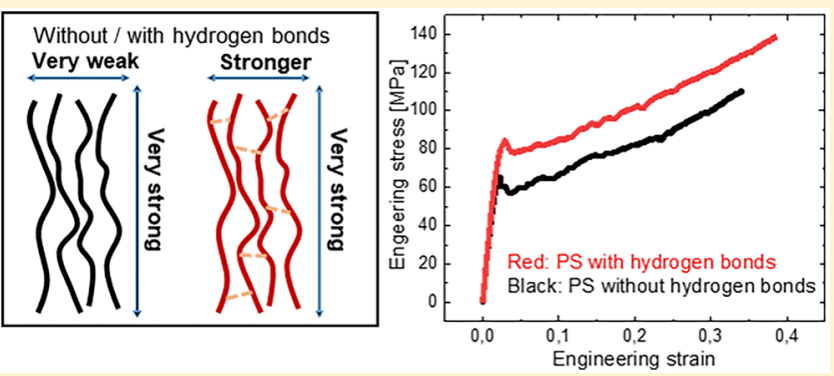
conditions. Addition of acid groups leads to an increase in $T_{\mathrm{g}}$, and this is documented by the detection of acid dimers in the glassy polymers. Importantly, linear viscoelastic measurements confirm that all the tested samples have a similar number of entanglements per chain $(\mathrm{Z})$, which suggests that the acid groups do not form hydrogen bonds at temperatures above $T_{\mathrm{g}}$. These are further confirmed by nonlinear extensional rheology of the samples in uniaxial extensional flow. Stretching melts of these polymers at a rate faster than the inverse Rouse time followed by rapid quenching below $T_{\mathrm{g}}$ leads to polymer fibers that remain highly flexible in analogy with nonmodified polystyrene. However, the resulting acid-containing polymer fibers have higher yield stress and ductility at room temperature compared to the nonmodified polystyrene fibers. This approach presents a facile route to improve mechanical properties of anisotropic glassy polystyrene.

\section{INTRODUCTION}

Polystyrene is a widely used thermoplastic polymer. In its common form, it is a brittle, amorphous, transparent material with a glass-transition temperature of around $100{ }^{\circ} \mathrm{C}$. Its thermostability allows it to be shaped in the melt in a variety of common methods such as injection molding and extrusion. The durable polymer is the basis for a range of commercial products due to its relative hardness and transparency. However, its brittleness limits the available applications. There are reports that temporary flexibility may be introduced in polystyrene by a process called mechanical rejuvenation, which is typically facilitated by compression in a two-roll milling process. ${ }^{1}$ However, this flexibility is temporary with a timescale of minutes to hours. Recently, our group reported that flexible polystyrene filaments can be obtained by stretching polystyrene melts at a rate faster than the inverse Rouse time, followed by rapid quenching below $T_{\mathrm{g}}$ (see Scheme 1A). ${ }^{2}$ The resulting highly oriented polystyrene fibers reach a much higher tensile strength than normal isotropic polystyrene and remain flexible after half a year. Apart from being interesting from a purely scientific point of view, the flexibility and high tensile strength make the resulting filaments potential candidates for use in applications where strength and flexibility are desirable. One possible drawback of the previously described fibers is that the properties are highly anisotropic; the fibers are very strong in the stretch direction but easily come apart perpendicular to the stretch direction. This anisotropy is achieved by uniaxial stretching faster than the inverse Rouse time followed by quenching whereby a high degree of orientation of the individual polymer chains is obtained (see Scheme 1A). In this extended, stressed state, chain relaxation and therefore strain localization are suppressed, which is reflected in reduced interchain interaction in the perpendicular direction. ${ }^{2,3}$ The resulting fibers become highly anisotropic.

The effect of forming hydrogen bonds to improve the mechanical properties of materials is perhaps most well known from wood, where the combination of relatively high strength and low density is related to the presence of multiple hydrogen bonds. ${ }^{4,5}$ Thus, interconnected polymer chains with transient hydrogen bonds are a topic of continued interest. ${ }^{6-8}$ Of particular interest is the temperature dependence of hydrogen bond exchange: at high temperatures, exchange is fast and the bonds have little effect on the viscoelastic properties. However, reducing the temperature leads to much slower exchange and the materials may behave as cross-linked networks. ${ }^{8}$

Here, we seek to increase the interchain interactions in the vitrified material by introducing a limited amount of hydrogen-

Received: September 4, 2019

Revised: November 11, 2019

Published: November 25, 2019 
Scheme 1. Enhancing Flexible Polystyrene Fiber Strength Perpendicular to the Stretch Direction ${ }^{a}$
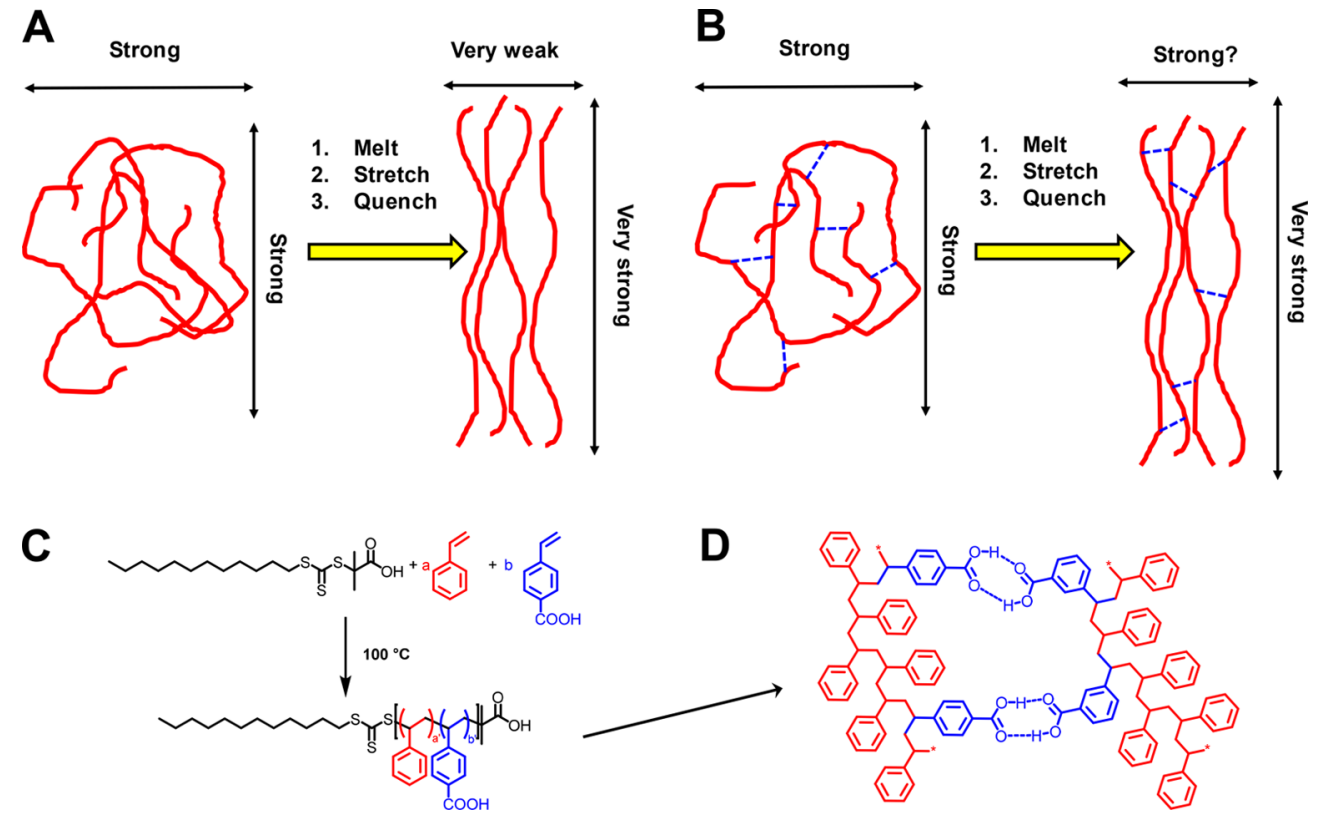

a (A) Schematic of flexible polystyrene fiber preparation according to ref 2 . These are strong and flexible in the stretch direction but weak perpendicular to the stretch direction. (B) Proposed enhancement of strength perpendicular to stretch direction by introduction of temperaturesensitive hydrogen bonds. (C) Synthesis of poly(styrene-co-4-vinylbenzoic acid) by RAFT polymerization. (D) Hydrogen bonding between two chains of poly(styrene-co-4-vinylbenzoic acid).

bonding sites in the form of carboxylic acid groups along the chains (see Scheme 1B). Since the strength of hydrogen bonds decreases with increasing temperature, ${ }^{8,9}$ the hypothesis is that the melt behaves very similar to a nonmodified polystyrene, whereas the vitrified material is reinforced by the presence of stronger interchain bonds. We believe that this is the first time that the effect of hydrogen bonds on vitrified material below $T_{\mathrm{g}}$ has been studied.

The introduction of carboxylic acid groups into well-defined copolymers has been accomplished using reversible additionfragmentation chain-transfer (RAFT) polymerization, which is tolerant to a wide range of functional groups. ${ }^{10-12}$ In particular, this method has been used to prepare amphiphilic poly(styrene- $b$-4-vinylbenzoic acid) block copolymers. ${ }^{13,14}$ Furthermore, statistical poly(styrene-co-4-vinylbenzoic acid) copolymers have been prepared by free radical polymerization either in homogeneous solution ${ }^{15,16}$ or in emulsion. ${ }^{17}$ However, the preparation of entangled, well-defined statistical poly(styrene-co-4-vinylbenzoic acid) by RAFT polymerization has not previously been the subject of detailed investigations to the best of our knowledge.

\section{EXPERIMENTAL SECTION}

Materials. Styrene (S, 99\%) was purchased from Sigma-Aldrich (Copenhagen, Denmark) and passed through a column of basic alumina to remove the polymerization inhibitor.

4-Vinylbenzoic acid (97\%) was purchased from TCI Europe (Zwijndrecht, Belgium) and recrystallized from ethanol before used.

2-(Dodecylthiocarbonothioylthio)-2-methylpropionic acid (98\%), tetrahydrofuran (HPLC grade), deuterated chloroform $\left(\mathrm{CDCl}_{3}\right.$, $99.8 \% \mathrm{D})$, trifluoroacetic acid $\left(\mathrm{CF}_{3} \mathrm{COOH}, 99 \%\right)$, acetic acid (99\%), and basic alumina (activated, Brockmann I) were purchased from Sigma-Aldrich (Copenhagen, Denmark) and used as received.

RAFT Synthesis of Copolymers. 2-(Dodecylthiocarbonothioylthio)-2-methylpropionic acid, chain transfer agent (1 equiv), 4-vinylbenzoic acid (VBA) (20-200 equiv), and styrene (2000 equiv) were mixed in a round-bottom flask. The mixture was degassed through three freeze-pump-thaw cycles, and the flask was filled with argon. Mixtures with more than $5 \% \mathrm{~mol} / \mathrm{mol} 4$-vinylbenzoic acid were found to be opaque at room temperature due to low solubility of 4vinylbenzoic acid in styrene. Upon heating to $100{ }^{\circ} \mathrm{C}$ to initiate the polymerization, all mixtures became transparent.

Kinetic samples were removed using argon-filled syringes and analyzed by size exclusion chromatography (SEC) and ${ }^{1} \mathrm{H}$ NMR. Once conversion had reached approximately $50 \%$, the reaction mixture was cooled to room temperature, diluted with 6 volumes ethyl acetate, and precipitated into methanol containing $1 \% \mathrm{v} / \mathrm{v}$ acetic acid. In the absence of acetic acid, a nonfilterable opaque suspension was obtained. The addition of acetic acid was found to break the suspension and led to macroscopic precipitation in approximately 5 min.

The resulting polymer was filtered and dried in a vacuum oven at $70{ }^{\circ} \mathrm{C}$ overnight.

The polystyrene without acid groups was prepared using the same method, omitting the 4-vinylbenzoic acid. The addition of acetic acid to the methanol was not necessary to obtain a filterable precipitate for this polymer.

Size Exclusion Chromatography. Size exclusion chromatography was carried out on a chromatographic system consisting of a Viscotek VE 2001 GPC solvent/sample module connected to a Viscotek TriSEC model 302 triple detector array (RI, light scattering, viscometer). The columns were a PL Guard and two PL gel mixed D columns from Polymer Laboratories connected in series; this column combination provides good resolution up to 300,000 Daltons and was calibrated with narrow molar mass polystyrene standards (PSS, Mainz, Germany). All samples and calibration standards were analyzed using a flow rate of $1 \mathrm{~mL} / \mathrm{min}$. Sample solutions were made up to $5 \mathrm{mg} / \mathrm{mL}$ to which was added $10 \mu \mathrm{L}$ of acetic acid to ensure complete dissolution of the acid-containing copolymers. Toluene was used as an internal flow rate marker.

Fourier Transform Infrared Spectroscopy Analysis. Fourier transform infrared (FTIR) spectroscopy was carried out using a Nicolet iS50 FTIR spectrometer (Thermo Fisher Scientific, USA). The wavenumber between 400 and $4000 \mathrm{~cm}^{-1}$ was recorded with 64 

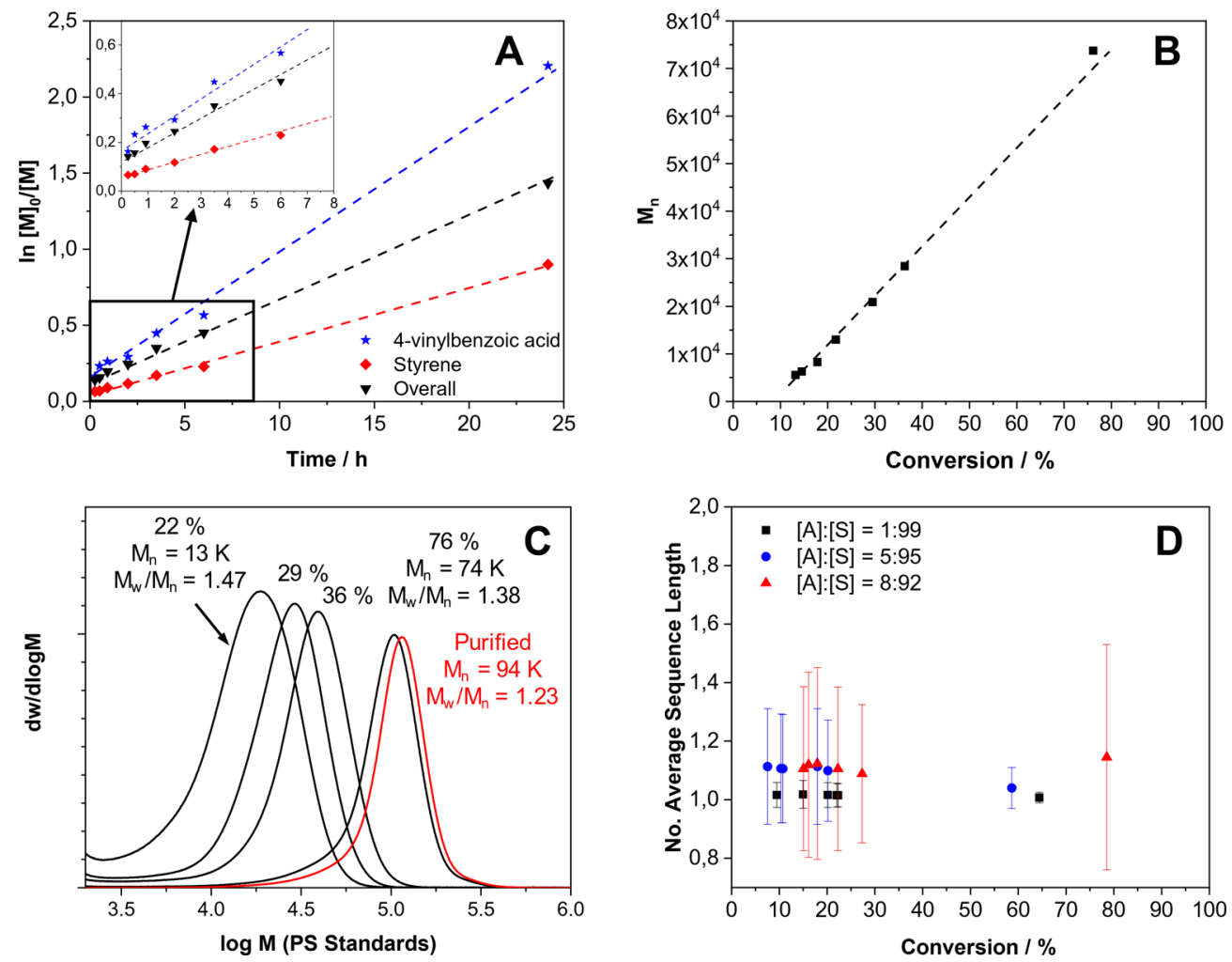

Figure 1. RAFT polymerization of styrene and 4-vinylbenzoic acid at $100{ }^{\circ} \mathrm{C}$. (A) Semilogarithmic plot of $[\mathrm{M}]_{0} /[\mathrm{M}]$ as a function of time (ratio 4vinylbenzoic acid $(A) /$ styrene $(S)=5: 95$ ). (B) Number-average molar mass (vs polystyrene standards) as a function of conversion (ratio 4vinylbenzoic acid (A)/styrene (S) = 5:95). (C) $d W / \operatorname{dlog} M$ versus $\log M$ at various conversions and for the purified polymer. (D) Number-average sequence length for 4-vinylbenzoic acid. Error bars on the sequence length are based on an estimated uncertainty on the ${ }^{1} \mathrm{H}$ NMR integrals of $10 \%$.

interferograms for each sample in either transmission or attenuated total reflection mode as indicated in the text.

Thermogravimetry. Thermogravimetry was carried out using a Discovery TGA (TA Instruments, USA). Samples $(10-20 \mathrm{mg})$ were heated in a nitrogen atmosphere with a heating rate of $10^{\circ} \mathrm{C} \mathrm{min}^{-1}$ from room temperature to $900{ }^{\circ} \mathrm{C}$.

Differential Scanning Calorimetry. Differential scanning calorimetry (DSC) measurements were performed on a Discovery DSC (TA Instruments, USA) in a nitrogen atmosphere with a heating and cooling rate of $10{ }^{\circ} \mathrm{C} \mathrm{min}^{-1}$. The weight range of tested sample was $2-5 \mathrm{mg}$, and all samples were heated to $180^{\circ} \mathrm{C}$, well above the glass-transition temperature, cooled, and finally heated to $200{ }^{\circ} \mathrm{C}$. Glass-transition temperatures were determined from the second heating curve.

Nuclear Magnetic Resonance Analysis. Nuclear magnetic resonance (NMR) spectroscopy was performed on a Bruker 300 $\mathrm{MHz}$ spectrometer. 4-Vinylbenzoic acid-containing copolymers (approximately $50 \mathrm{mg}$ ) were dissolved in a premade 95:5 $\mathrm{v} / \mathrm{v}$ mixture of $\mathrm{CDCl}_{3}$ and $\mathrm{CF}_{3} \mathrm{COOH}(0.6 \mathrm{~mL})$. Data were analyzed using TopSpin version $3.5 \mathrm{pl} 7$ from Bruker.

Evaluation of Reactivity Ratios from ${ }^{1} \mathrm{H}$ NMR Data. The overall conversion was calculated from the ${ }^{1} \mathrm{H}$ NMR spectra by comparing the ratio between integrals of bands assigned to monomers (see Figure S1) and the sum of integrals of bands assigned to both monomer and polymer. Specifically, the conversion was determined from the integrals of bands assigned to vinylic monomers between 5 and $6 \mathrm{ppm}$ (two sets of signals due to 4-vinylbenzoic acid and styrene) and the integrated bands assigned to the aromatic residue of poly(4-vinylbenzoic acid) at 7.7-7.9 $\mathrm{ppm}(2 \mathrm{H})$ and to the aromatic residue of polystyrene at $6.9-7.2 \mathrm{ppm}(3 \mathrm{H})$. These bands were assigned by the help of COSY (see Figure S2). The conversion of 4vinylbenzoic acid was determined from the sum of integrals of the bands assigned to the vinylic protons for this monomer at 5.4 and 5.9 ppm $(2 \mathrm{H})$ and the integral of the band assigned to the polymer at
7.7-7.9 ppm (2H). Similarly, the conversion of styrene was determined from the sum of the integrals of the bands assigned to the vinylic protons for this monomer at 5.2 and $5.7 \mathrm{ppm}(2 \mathrm{H})$ and the integral of the band assigned to polystyrene at $6.9-7.2 \mathrm{ppm}(3 \mathrm{H})$.

The ratios between monomers were used to calculate the instantaneous monomer $\left(f_{\mathrm{A}}, f_{\mathrm{S}}\right)$ and copolymer mole fractions $\left(F_{\mathrm{A}}\right.$ $\left.F_{S}\right)$ for 5-7 samples per experiment. According to the Mayo-Lewis equation, the copolymer mole fractions are related to the monomer mole fractions as

$$
F_{\mathrm{A}}=1-F_{\mathrm{S}}=\frac{r_{\mathrm{A}} f_{\mathrm{A}}^{2}+f_{\mathrm{A}} f_{\mathrm{S}}}{r_{\mathrm{A}} f_{\mathrm{A}}^{2}+2 f_{\mathrm{A}} f_{\mathrm{S}}+r_{\mathrm{S}} f_{2}^{2}}
$$

where $r_{\mathrm{A}}$ and $r_{\mathrm{S}}$ are the reactivity ratios. To fit the data to the two reactivity ratios, the difference between the measured and the calculated copolymer composition was minimized with respect to $r_{\mathrm{A}}$ and $r_{\mathrm{S}}$ for each experiments using the "GRG Nonlinear" method in the "Solver" function in the Microsoft Excel software package with a required convergence of 0.0001 . This was repeated with data from four different polymerization experiments with [4-vinylbenzoic acid]/ [styrene] ratios ranging from 0.01 to 0.08 . The four sets of reactivity ratios were averaged, and the uncertainty was estimated as the standard error.

Mechanical Spectroscopy. The linear viscoelastic (LVE) properties of the polymer melts were obtained from small amplitude oscillatory shear measurements. An $8 \mathrm{~mm}$ plate-plate geometry was used on an ARES-G2 rheometer from TA Instruments. The measurements for the melts were performed at temperatures between 130 and $170{ }^{\circ} \mathrm{C}$ under nitrogen. For each sample, the data were shifted to a master curve at $150{ }^{\circ} \mathrm{C}$.

Extensional Stress Measurement. The nonlinear rheological behaviors in extensional flow were studied above $T_{\mathrm{g}}$ using a filament stretching rheometer (VADER, Rheo Filament ApS) under a constant strain rate, where both normal force $F(t)$ and diameter evolution 
$2 R(t)$ were measured. Prior to a measurement, all samples were molded into cylindrical specimens with a fixed radius $R_{0}(2.7$ or 4 $\mathrm{mm})$. The initial sample length $L_{0}$ was controlled by the sample amount, giving an aspect ratio $\left(\Delta_{0}=L_{0} / R_{0}\right)$ around 0.5 . All the tests were carried out at $T_{\mathrm{g}}+30{ }^{\circ} \mathrm{C}$ under nitrogen protection.

The Hencky strain of the midfilament plane is calculated as

$$
\varepsilon_{\mathrm{H}}(t)=-2 \ln \left(R(t) / R_{0}\right)
$$

and the corrected stress with respect to shear component in the startup extensional flow is calculated as ${ }^{18}$

$$
\begin{aligned}
& <\sigma_{\mathrm{zz}}-\sigma_{\mathrm{rr}}>=\frac{F(t)-\frac{m g}{2}}{\pi R(t)^{2}} \\
& \times \frac{1}{1+\left(R(t) / R_{0}\right)^{10 / 3} \exp \left(-\Delta_{0}{ }^{3}\right) /\left(3 \Delta_{0}{ }^{2}\right)}
\end{aligned}
$$

while the strain rate $\dot{\varepsilon}=\mathrm{d} \varepsilon / \mathrm{d} t$ is constant during experiment, the extensional stress growth coefficient is defined as

$$
\bar{\eta}^{+}=<\sigma_{\mathrm{zz}}-\sigma_{\mathrm{rr}}>/ \dot{\varepsilon} .
$$

To prepare specimens used in mechanical tests, the polymer melts were stretched at a rate faster than the inverse Rouse time to a Hencky strain of 3.5 and quenched by nitrogen flow below $T_{g}$, which preserves the molecular conformation. The specimens were taken out for tensile and 3-point bending tests.

Tensile and 3-Point Bending Test. Tensile tests were carried out at a strain rate of $0.001 \mathrm{~s}^{-1}$ on Instron at room temperature. The samples have a cylindrical form with a diameter around $0.3 \mathrm{~mm}$. The engineering strain and stress are calculated as

$$
\varepsilon_{\text {Eng }}=\frac{l(t)-l_{0}}{l_{0}}
$$

and

$$
\sigma_{\text {Eng }}=\frac{F(t)}{\pi r_{0}{ }^{2}}
$$

where $l_{0}$ and $r_{0}$ are the initial length between two clamps $(5 \mathrm{~cm})$ and radius of specimen, respectively. The strain rate $\dot{\varepsilon}_{\mathrm{Eng}}=\mathrm{d} \varepsilon_{\mathrm{Eng}} / \mathrm{d} t$ is constant by imposing constant velocity of upper clamp. It is noted that at small deformation, the engineering strain and Hencky strain are equivalent as indicated in the following equation

$$
\begin{aligned}
\varepsilon_{\mathrm{H}} & =\ln \frac{l(t)}{l_{0}}=\ln \left(\frac{l_{0}}{l_{0}}+\frac{l(t)-l_{0}}{l_{0}}\right)=\ln \left(1+\varepsilon_{\text {Eng }}\right) \\
& =\varepsilon_{\text {Eng }}+o(\varepsilon)
\end{aligned}
$$

3-point bending tests were carried out on an RSA3 dynamic mechanical analyzer from TA Instruments. The diameters of cylindrical samples are between 0.6 and $0.8 \mathrm{~mm}$. All tests were performed at a constant velocity of $0.005 \mathrm{~mm} / \mathrm{s}$ at room temperature. The stress and strain are calculated as

$$
\begin{aligned}
& \sigma=\frac{P L}{\pi R^{3}} \\
& \varepsilon=\frac{12 R \delta}{L^{2}}
\end{aligned}
$$

where $P$ is the measured force, $L$ is the length between supports, $R$ is the radius of specimen, and $\delta$ is deflection. Detailed deduction of calculation of the stress and strain can be found in the Supporting Information.

\section{RESULTS AND DISCUSSION}

Synthesis of Poly(styrene-co-4-vinylbenzoic acid). Copolymers of styrene (S) and 4-vinylbenzoic acid (A) were prepared according to Scheme 1C, following a general procedure for RAFT polymerization of styrene in bulk. ${ }^{19}$
Table 1. Data for the Synthesized Poly(styrene-co-4vinylbenzoic acid) Copolymers

$\begin{array}{lccrrr}\begin{array}{c}\text { feed } \\ \text { composition }\end{array} & \begin{array}{c}{ }^{1} \mathrm{H} \text { NMR } \\ \text { composition }\end{array} & \begin{array}{c}\text { monomer } \\ \text { conversion } \\ (\%)^{b}\end{array} & M_{\mathrm{n}}, \mathrm{SEC}^{\mathrm{c}} & \begin{array}{c}M_{\mathrm{w}} / M_{\mathrm{n}}, \\ \mathrm{SEC}^{\mathrm{c}}\end{array} & \begin{array}{c}T_{\mathrm{g}} \\ \left({ }^{\circ} \mathrm{C}\right)\end{array} \\ \mathrm{PS}_{0.99} \mathrm{~A}_{0.01} & \mathrm{PS}_{0.98} \mathrm{~A}_{0.02} & 50 \pm 5 & 64,900 & 1.19 & 106 \\ \mathrm{PS}_{0.97} \mathrm{~A}_{0.03} & \mathrm{PS}_{0.95} \mathrm{~A}_{0.05} & 56 \pm 5 & 91,900 & 1.23 & 114 \\ \mathrm{PS}_{0.97} \mathrm{~A}_{0.03} & \mathrm{PS}_{0.94} \mathrm{~A}_{0.06} & 52 \pm 7 & 75,600 & 1.23 & 116 \\ \mathrm{PS}_{0.95} \mathrm{~A}_{0.05} & \mathrm{PS}_{0.91} \mathrm{~A}_{0.09} & 56 \pm 5 & 94,000 & 1.23 & 122 \\ \mathrm{PS}_{0.94} \mathrm{~A}_{0.06} & \mathrm{PS}_{0.88} \mathrm{~A}_{0.12} & \mathrm{~N} / \mathrm{M} & 82,200 & 1.28 & 132 \\ \mathrm{PS}_{0.92} \mathrm{~A}_{0.08} & \mathrm{PS}_{0.86} \mathrm{~A}_{0.14} & 71 \pm 5 & 104,200 & 1.29 & 134 \\ \mathrm{PS}_{0.90} \mathrm{PA}_{0.10} & \mathrm{PS}_{0.84} \mathrm{~A}_{0.16} & \mathrm{~N} / \mathrm{M} & 117,000 & 1.33 & 157 \\ \mathrm{PS} & \mathrm{PS} & 85 \pm 13 & 86,100 & 1.65 & 103\end{array}$

${ }^{a 1} \mathrm{H}$ NMR in $\mathrm{CDCl}_{3}$ containing $10 \mu \mathrm{L} / \mathrm{mL}$ trifluoroacetic acid. ${ }^{b}$ The overall monomer conversion at termination as determined by ${ }^{1} \mathrm{H}$ $\mathrm{NMR}$ in $\mathrm{CDCl}_{3}$ with $5 \% \mathrm{v} / \mathrm{v}$ trifluoroacetic acid. The uncertainties are based on an estimated uncertainty on the ${ }^{1} \mathrm{H}$ NMR integrals of $10 \%$. $\mathrm{N} / \mathrm{M}$ : not measured. ${ }^{c}$ Size exclusion chromatography in tetrahydrofuran against polystyrene standards. The sample solution contained $10 \mu \mathrm{L} / \mathrm{mL}$ acetic acid to ensure dissolution of acidcontaining copolymers.

The conversion of each monomer and the copolymer composition could be followed simultaneously by ${ }^{1} \mathrm{H}$ NMR (see Figure S1). The conversion was deliberately kept relatively low because this kept polymerization times short (around $24 \mathrm{~h}$ ) and because the redissolution required for workup of the viscous reaction mixture was significantly faster than the polymer taken to a near $100 \%$ conversion. In addition, the relatively low conversion ensured that the monomer distribution along the chain did not become exceedingly asymmetric (see discussion below). Figure 1A shows that both monomers follow pseudo-first-order kinetics as indicated by a linear semilogarithmic plot, but 4-vinylbenzoic acid polymerizes faster under these conditions. Results obtained by size exclusion chromatography show a linear increase in the molar mass with conversion (Figure 1B) as well as a decrease in molar mass distribution (Figure 1C), which are indications of a controlled polymerization. ${ }^{20}$ The final dispersities are comparable to those of polystyrenes of comparable molar mass prepared by RAFT polymerization. ${ }^{21}$ Close inspection of the molecular mass distributions in Figure $1 \mathrm{C}$ reveals that the copolymers have a significant low molar mass fraction, which indicates termination (by noncombinatory reactions). Precipitation into methanol removes most of the low molecular mass material (see Figure 1C, red trace). The purified polymers therefore generally have dispersities below 1.4 (see Table 1), which is low compared to polymers prepared by free radical polymerization.

Chain recombination is a commonly observed termination mechanism in radical-mediated styrene polymerization. ${ }^{22,23}$ This mechanism leads to chains with twice the molecular mass to that targeted. However, the high molar mass fraction due to chain recombination is relatively small under the polymerization conditions employed here (see Figure 1C). This is important since small amounts of high-molecular-mass chains are known to significantly influence polymer melt rheology. ${ }^{24-26}$

The faster incorporation of 4-vinylbenzoic acid agrees with the literature, where copolymers based on the same two monomers prepared by free radical polymerization in solution were found to have reactivity ratios of $r_{\mathrm{S}}=0.28$ and $r_{\mathrm{A}}=$ 1.04. ${ }^{15}$ In the present work, it was found that ${ }^{1} \mathrm{H}$ NMR 

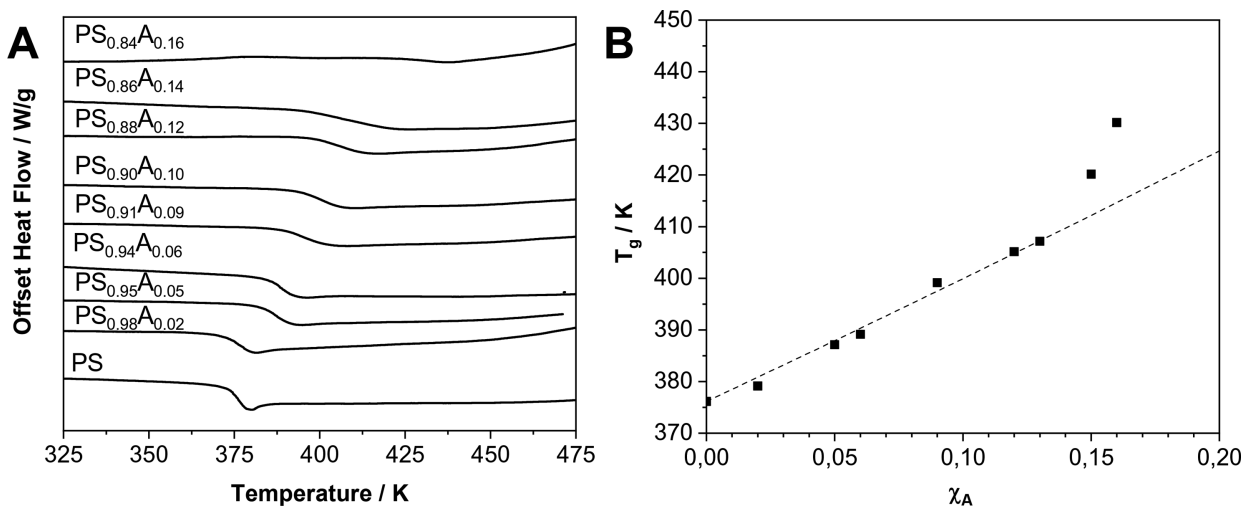

Figure 2. (A) DSC traces, second heat cycle used for assessing $T_{g}$. Heat $/$ cool rate: $10 \mathrm{~K} / \mathrm{min}$. (B) Glass-transition temperature, $T_{g}$, as a function of 4-vinylbenzoic acid content. The dotted line corresponds to a fit to the Fox equation including data points up to an acid fraction of 0.14 .
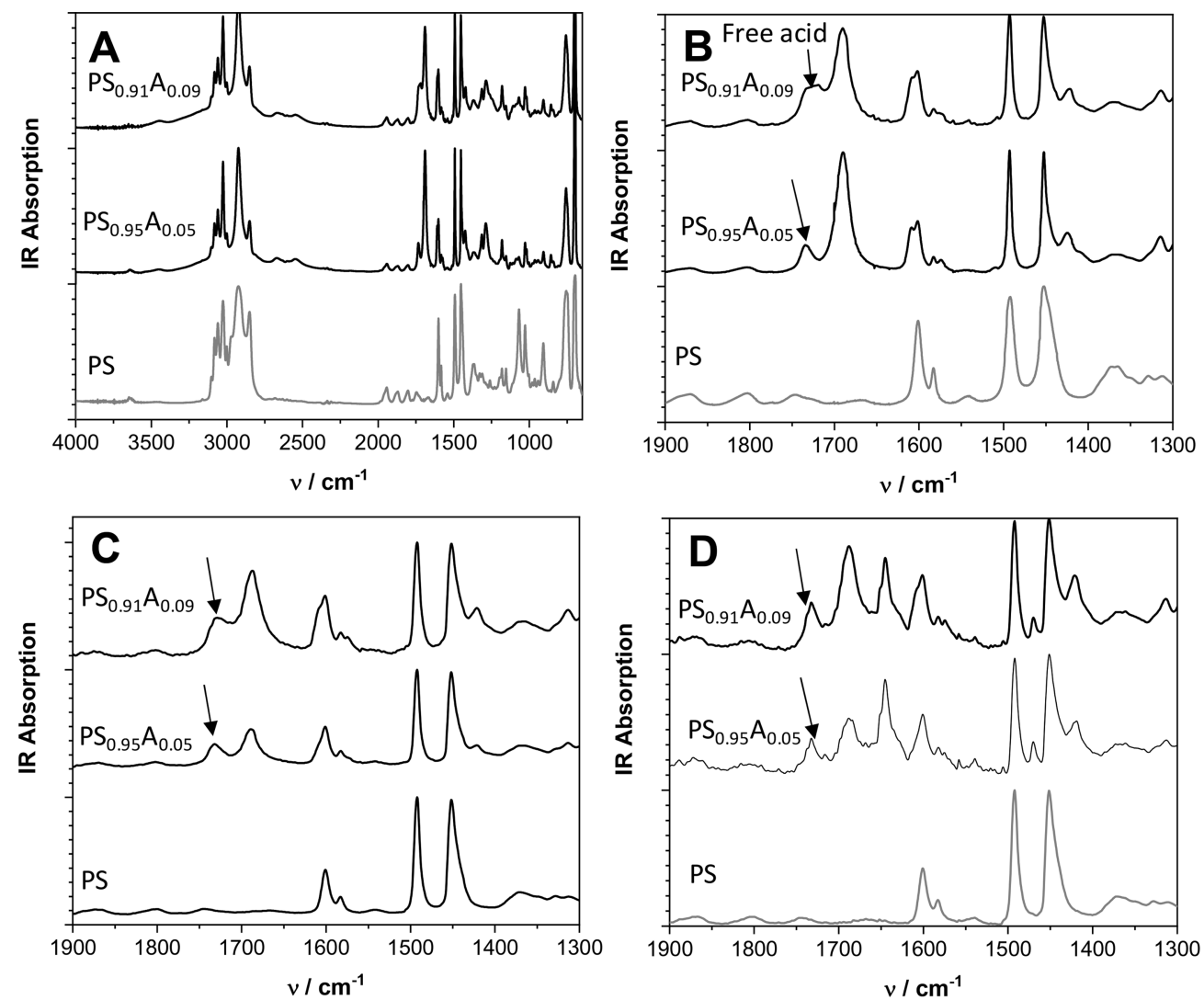

Figure 3. (A) IR absorption spectra from $700-4000 \mathrm{~cm}^{-1}$ of free-standing PS, $\mathrm{PS}_{0.95} \mathrm{~A}_{0.05}$, and $\mathrm{PS}_{0.91} \mathrm{~A}_{0.09}$ films cast from THF obtained in transmission mode. (B) Close-up of the spectral region containing the $\mathrm{C}=\mathrm{O}$ stretch from the spectra in (A). The arrows indicate the carbonyl stretch from free (nonhydrogen-bonded) acid carbonyl groups. (C) $\mathrm{C}=\mathrm{O}$ stretch region of melt-processed pellets of $\mathrm{PS}, \mathrm{PS}_{0.95} \mathrm{~A}_{0.05}$, and $\mathrm{PS} \mathrm{S}_{0.91} \mathrm{~A}_{0.09}$ obtained by attenuated total reflectance (ATR) from the surface. (D) $\mathrm{C}=\mathrm{O}$ stretch region of stretched fibers of $P S, \mathrm{PS}_{0.95} \mathrm{~A}_{0.05}$, and $\mathrm{PS}_{0.91} \mathrm{~A}_{0.09}$ obtained by attenuated total reflectance (ATR) from the surface.

measurements of kinetics samples allowed simultaneous evaluation of both monomer and copolymer compositions (see Figure $\mathrm{S} 1$ ). These data could be used to evaluate reactivity ratios of $r_{\mathrm{S}}=0.33 \pm 0.10$ and $r_{\mathrm{A}}=0.98 \pm 0.06$ as detailed in the Experimental Section (see the Supporting Information). Thus, there is good agreement between the two sets of values, especially when differences in the polymerization conditions are taken into consideration: The reactivity ratios in ref 15 are derived from a polymerization in ethanolic solution at $60{ }^{\circ} \mathrm{C}$ using a free radical initiator. This is in contrast to the results presented here, where the polymerization is carried out in bulk styrene at $100{ }^{\circ} \mathrm{C}$, using styrene autopolymerization. Thus, both the initiating species, temperature, and concentration are different. The presence of a chain transfer agent may also have an influence. ${ }^{2 f}$

The faster incorporation of 4-vinylbenzoic acid compared to styrene into the copolymer may lead to an asymmetry in the polymer composition along the chains, where long sequences of the former monomer may form. The presence of such sequences may affect the melt properties of the polymer and affect the regularity of the interchain bonds and thereby the mechanical properties. Knowledge of the reactivity ratios allows calculation of the number average sequence length of monomer $\mathrm{A}$ as a function of conversion ${ }^{28}$ 

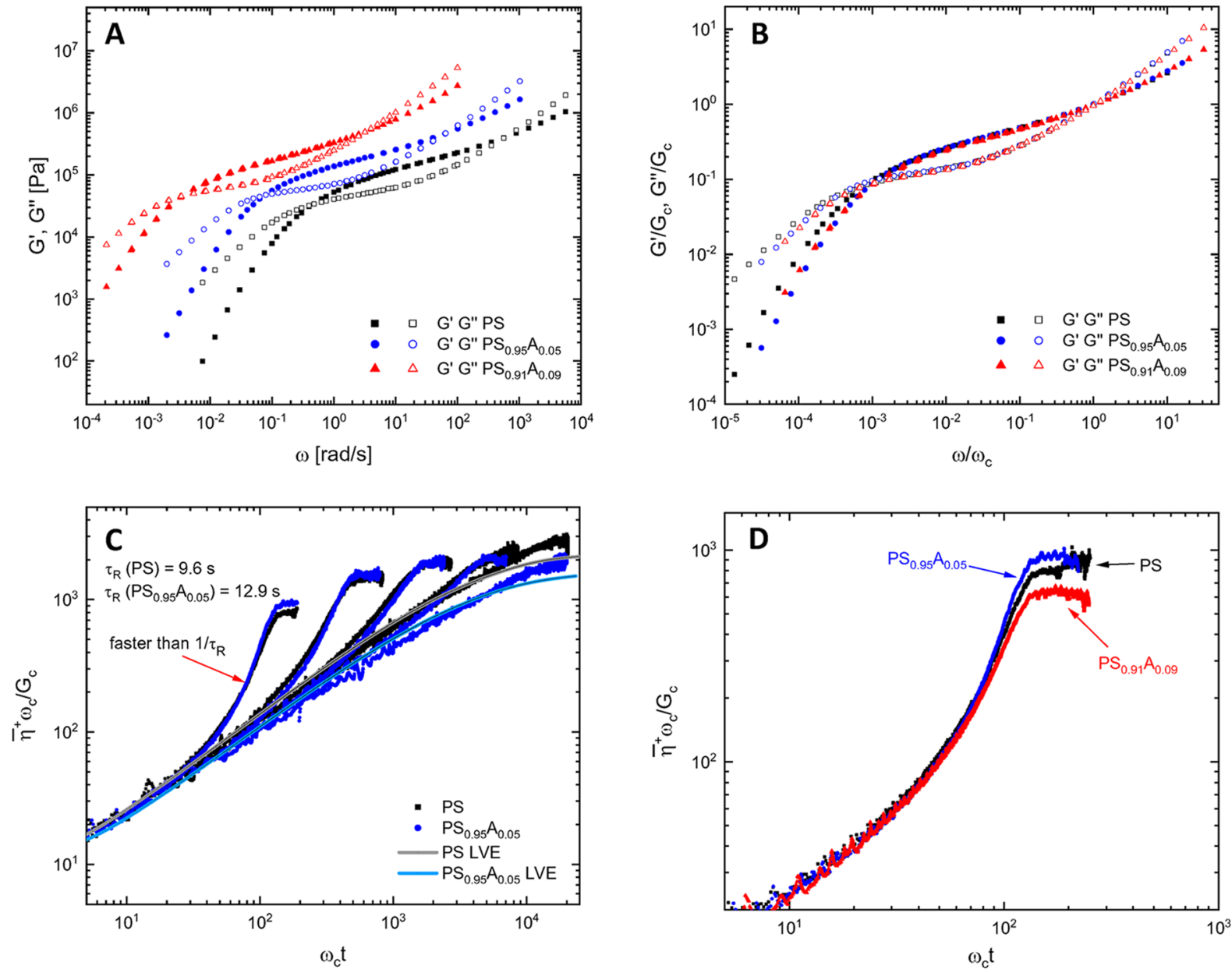

Figure 4. Rheology of polystyrene and poly(styrene-co-4-vinyl benzoic acid) copolymers. (A) LVE data referenced at $150{ }^{\circ} \mathrm{C}$. (B) LVE data after normalization to the modulus and frequency at high-frequency crossover point, referenced at $150{ }^{\circ} \mathrm{C}$. (C) Comparison of normalized extensional stress growth coefficient for PS and $\mathrm{PS}_{0.95} \mathrm{~A}_{0.05}$. Strain rates for PS at $130{ }^{\circ} \mathrm{C}$ (from left to right): $0.2,0.06,0.02,0.006$, and $0.002 \mathrm{~s}^{-1}$. Strain rates for $\mathrm{PS}_{0.95} \mathrm{~A}_{0.05}$ at $140{ }^{\circ} \mathrm{C}$ (from left to right): 0.12, 0.036, 0.012, 0.0036, and $0.0012 \mathrm{~s}^{-1}$. (D) Comparison of normalized extensional stress growth coefficient for PS, $\mathrm{PS}_{0.95} \mathrm{~A}_{0.05}$, and $\mathrm{PS}_{0.91} \mathrm{~A}_{0.09}$. Strain rate for PS at $130{ }^{\circ} \mathrm{C}: 0.2 \mathrm{~s}^{-1}$. Strain rate for $\mathrm{PS}_{0.95} \mathrm{~A}_{0.05}$ at $140{ }^{\circ} \mathrm{C}$ : $0.12 \mathrm{~s}^{-1}$. Strain rate for $\mathrm{PS}_{0.91} \mathrm{~A}_{0.09}$ at $150{ }^{\circ} \mathrm{C}: 0.062 \mathrm{~s}^{-1}$.

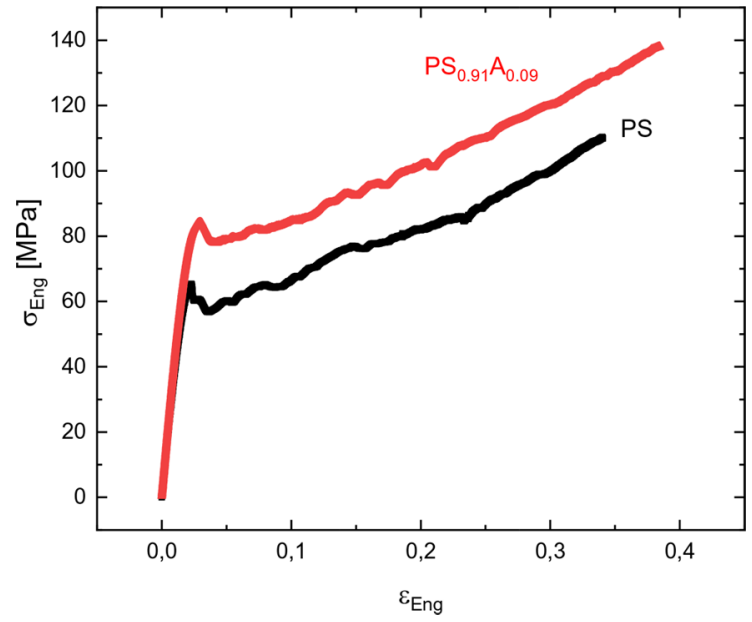

Figure 5. Tensile test for specimens $\mathrm{PS}$ and $\mathrm{PS}_{0.91} \mathrm{~A}_{0.09}$ at room temperature (strain rate, $0.001 \mathrm{~s}^{-1}$ ).

$$
\bar{l}_{\mathrm{A}}=\frac{\text { total number of A units }}{\text { total number of A sequences }}=r_{\mathrm{A}} \frac{f_{\mathrm{A}}}{f_{\mathrm{S}}}-1
$$

where $r_{\mathrm{A}}$ is the reactivity ratio and $f_{\mathrm{A}}$ and $f_{\mathrm{S}}$ are mole fractions of $\mathrm{A}$ and $\mathrm{S}$, respectively, (as determined by ${ }^{1} \mathrm{H}$ NMR). An analogous expression exists for $S .^{28}$ For copolymers with feed acid contents of $0.01,0.05$, and 0.08 , the number-average sequence lengths of 4-vinylbenzoic acid as a function of conversion have been plotted in Figure 1D. The plot reveals an average length of 4-vinyl benzoic acid units close to unity, which indicates that block formation is suppressed even at the highest acid feed content. The styrene sequence length increases with conversion, especially for acid feed ratios of 0.01 and 0.05 (see Figure S3). This is expected since the 4vinylbenzoic acid is depleted early in the polymerization. Thus, termination at relatively low conversion also suppresses the asymmetric monomer distribution to some extent.

Thermal Properties of Poly(styrene-co-4-vinylbenzoic acid). The DSC traces in Figure $2 \mathrm{~A}$ reveal that incorporation of 4-vinylbenzoic acid leads to an increase in the glasstransition temperature. In addition, the transition seems to broaden with increasing amounts of acid. The increase in the glass-transition temperature has been observed for other carboxylic acid-containing copolymers and is generally ascribed to a reduction in free volume. ${ }^{8}$ Figure $2 \mathrm{~B}$ shows the measured glass-transition temperatures as a function of acid fraction. The 

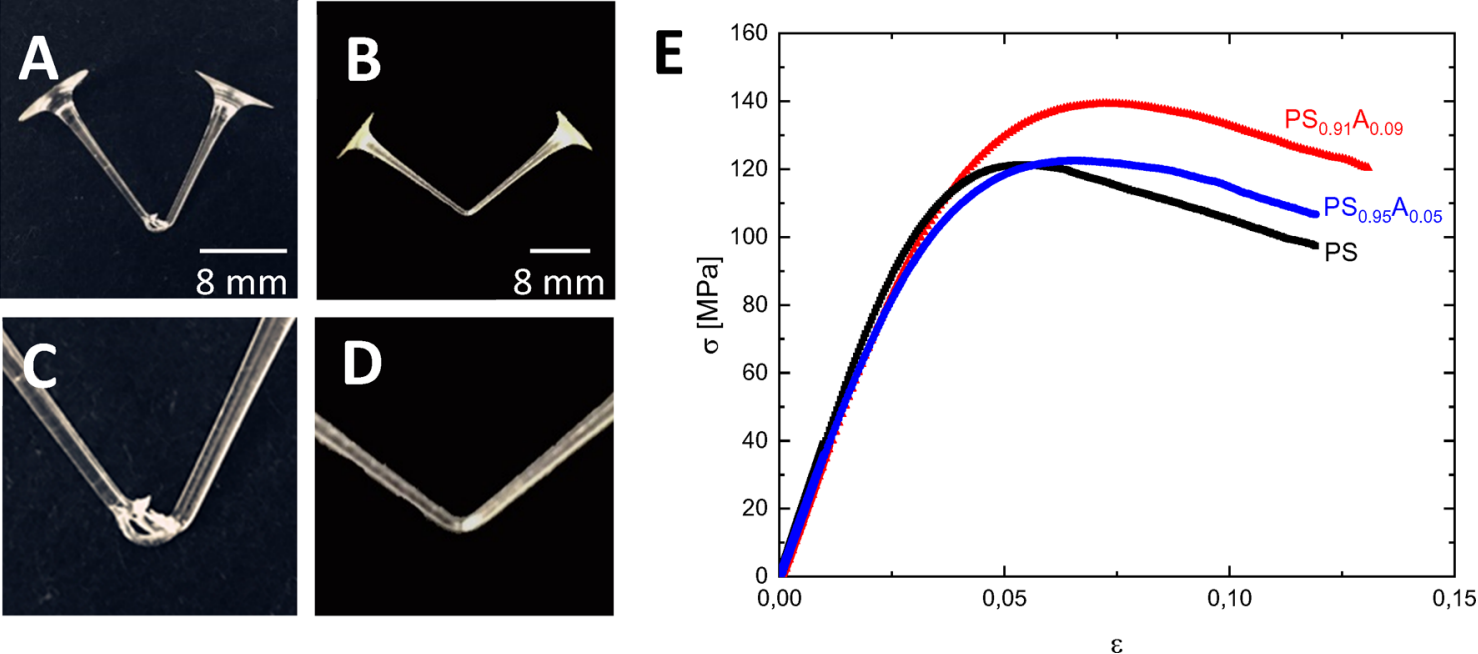

Figure 6. 3-point bending of flexible samples. (A, C) PS bent to a point where full recovery is not possible. (B, D) PS ${ }_{0.95} \mathrm{~A}_{0.05}$ bent to a point where full recovery is not possible. (E) 3-point bending for specimens PS, $\mathrm{PS}_{0.95} \mathrm{~A}_{0.05}$ and $\mathrm{PS}_{0.91} \mathrm{~A}_{0.09}$ at room temperature $(\mathrm{v}=0.005 \mathrm{~mm} / \mathrm{s})$. All samples are stretched to a Hencky strain of 3.5 in the melt, followed by rapid quenching by cooling to room temperature.

Table 2. Strain at Maximum Stress as Measured by 3-Point Bending

\begin{tabular}{lc}
\multicolumn{1}{c}{ sample } & strain at maximum stress \\
$\mathrm{PS}$ & $5.31 \% \pm 0.05 \%$ \\
$\mathrm{PS}_{0.95} \mathrm{~A}_{0.05}$ & $6.35 \% \pm 0.21 \%$ \\
$\mathrm{PS}_{0.91} \mathrm{~A}_{0.09}$ & $7.35 \% \pm 0.16 \%$
\end{tabular}

dotted line is prepared by fitting the data points to the Fox equation, which assumes that the glass transition of the copolymer is related to the glass transition of the individual homopolymers and their relative weight fractions ${ }^{29}$

$$
1 / T_{\mathrm{g}}=w_{\mathrm{A}} / T_{\mathrm{g}, \mathrm{A}}+w_{\mathrm{S}} / T_{\mathrm{g}, \mathrm{S}}
$$

The glass-transition temperature of the poly(4-vinylbenzoic acid) (PVBA) homopolymer has been reported to be 250 ${ }^{\circ} \mathrm{C},{ }^{30}$ but this value does not seem to be directly measured. A direct measurement of such high glass-transition temperature is not possible since side reactions such as dehydration, decarboxylation, and combustion are expected to be dominant at temperatures significantly close to $400{ }^{\circ} \mathrm{C}$ by analogy to copolymers of styrene and various carboxylic acids (see also thermogravimetry in Figure S4). ${ }^{21,31}$

Rather than using the literature value, the data points up to an acid fraction of 0.14 in Figure $2 \mathrm{~B}$ were fitted to the Fox equation. This gave a $T_{\mathrm{g}}$ of $390^{\circ} \mathrm{C}(663 \mathrm{~K})$. The fit is excellent for an acid fraction up to 0.14 , but significant deviation is seen at a fraction of 0.16. As shown in Figure 2A, the transition broadens with increasing acid content and as a consequence, so does the uncertainty on the evaluated $T_{\mathrm{g}}$. This broadening is related to the dissociation of acid dimers through hydrogen bonding, as previously reported for copolymers of styrene and methacrylic acid; acid unimers and dimers are in equilibrium, which is governed by the temperature and the concentration. Increasing the temperature leads to gradual dissociation of the dimers, which is reflected in the DSC curves. However, the dimer formation is suppressed and contributes less at lower acid content. 32,33

Thus, the Fox equation fails for predicting the glass transition of copolymers through the entire range of copolymer compositions due to the interacting nature of the polymer chains. Nevertheless, the "fitted" $T_{g}$ of $390{ }^{\circ} \mathrm{C}$ is useful for prediction of the glass-transition temperatures of copolymers with an acid fraction of less than 0.14 , which allows establishing a processing window.

The increased $T_{\mathrm{g}}$ reduces the window of processing; polystyrene degrades in inert atmosphere above $200{ }^{\circ} \mathrm{C}^{21}$ and dehydration of copolymers of styrene and carboxylic acids has been reported at $180{ }^{\circ} \mathrm{C} .{ }^{31}$ However for meltprocessing polymers, it is necessary to work above the glasstransition temperature without (significantly) degrading the copolymer. In addition, the elucidation of polymer properties such as entanglement length and Rouse time often requires the measurement of polymer melts at different temperatures. ${ }^{34}$ Furthermore, initial experiments indicated that heating a copolymer with an acid fraction of 0.1 to more than $200^{\circ} \mathrm{C}$ for times relevant to rheology experiments (minutes to hours) in a nitrogen atmosphere led to an increase in the storage modulus, which may indicate cross-linking (see Figure S5). Together with experimental difficulties such as prestretch and slip-off in extension measurement, it was not practical to use copolymers with a VBA fraction higher than approximately 0.1 to measure viscoelastic behavior and process.

Importantly, none of the DSC traces show any signs of crystallization. Crystallization is not expected since it is normally encountered in syndiotactic and isotactic polymers only. ${ }^{35}$ All the polymers here are prepared by RAFT polymerization, which in essence is a free radical polymerization technique that, in the absence of additives, is expected to give atactic polymers. ${ }^{36}$

Hydrogen Bonding in Vitrified Poly(styrene-co-4vinylbenzoic acid). Figure $3 \mathrm{~A}$ shows absorption IR spectra obtained by transmission through thin, free-standing solventcast films of polystyrene and poly(styrene-co-4-vinylbenzoic acid). The broad peaks above and below the $\mathrm{C}-\mathrm{H}$ stretch at $3000 \mathrm{~cm}^{-1}$ (at approximately 3200 and $2600 \mathrm{~cm}^{-1}$ ) can be assigned to free and bonded $\mathrm{OH}$ stretch, in accordance to assignments on structurally related copolymers of styrene and maleic acid. ${ }^{31}$ Following this work, the broad peak at 3400 $\mathrm{cm}^{-1}$ can be assigned to water bonded to acid $\mathrm{OH}$ groups. Additional information can be gained by considering the resonances associated with $\mathrm{C}=\mathrm{O}$ stretch around $1700 \mathrm{~cm}^{-1}$. 
These are significantly narrower and more resolved (see Figure 3B). The minor peak above $1700 \mathrm{~cm}^{-1}$ (marked with an arrow in Figure 3) is assigned to the $\mathrm{C}=\mathrm{O}$ stretch of the free carboxylic acid both in copolymers of styrene and maleic acid ${ }^{31}$ and in benzoic acid solutions. ${ }^{37}$ Similarly, the major peak just below $1700 \mathrm{~cm}^{-1}$ has been assigned to hydrogen-bonded acid dimers both in solid polymers and in solution. ${ }^{31,37}$ Although direct calculation of the ratio between free and dimeric acid groups is difficult due to lack of knowledge of their exact oscillator strengths, the spectra in Figure 3 indicate that dimer formation is dominant but not complete in the solid solventcast films.

Examining the surface of melt-processed polymer films using ATR-FTIR may give an indication of whether the hydrogen bonding in the solid is different in solvent-cast and molded films. As Figure 3C shows, dimer formation still appears to be significant in melt-processed films, although the polymers with an acid fraction of 0.05 has a band due to an acid dimer that is less dominant than in the spectrum obtained from the solventcast film. On the other hand, the ATR-FTIR spectrum of the melt-processed copolymer with an acid fraction of 0.09 is comparable to the corresponding transmission spectrum of the solvent-cast film. One possible explanation is that the higher concentration of acid groups in the latter polymer favors the chance of dimer formation.

Rheology. Storage modulus $\mathrm{G}^{\prime}$ and loss modulus $\mathrm{G}^{\prime \prime}$ of PS, $\mathrm{PS}_{0.95} \mathrm{~A}_{0.05}$, and $\mathrm{PS}_{0.91} \mathrm{~A}_{0.09}$ as a function of angular frequency $\omega$ at a reference temperature of $150{ }^{\circ} \mathrm{C}$ are shown in Figure 4A. These master curves have similar shape with a horizontal shift that is due to the difference in $T_{\mathrm{g}}{ }^{38}$ To compensate for the $T_{\mathrm{g}}$ difference and compare the three polymers directly, the frequency and modulus are normalized by the crossover point at high frequency $\left(\omega_{c}\right.$ and $\left.G_{c}\right)$ for each sample (see Figure $4 \mathrm{~B})$. The three normalized curves overlap, indicating that the number of entanglements per chain is identical. ${ }^{39}$ Since the molar masses are comparable for the three polymers (see Table 1), the results suggest that the acid groups do not form hydrogen bonds above $T_{\mathrm{g}}$.

Figure 4C compares the nonlinear extensional behavior of PS and $\mathrm{PS}_{0.95} \mathrm{~A}_{0.05}$. Due to the difference in glass-transition temperature of the two samples, it was necessary to measure the nonlinear extensional behavior at different stretch rates and temperatures (see the Supporting Information). The data shown have been normalized by their high-frequency crossover for comparison. The LVE envelope in the figure is calculated from the linear viscoelastic data (see the Supporting Information) and is a prediction of infinitely slow extensional flow. By increasing the stretch rate, the strain hardening effect is more evident since the polymer chains become more oriented and stretched. These two samples show similar extensional behavior at high temperatures above $T_{\mathrm{g}}$. Of particular interest are samples that have been stretched faster than the inverse Rouse time, which correspond to the curves peaking at lower $\omega_{\mathrm{c}} t$ in Figure 4C. These have the highest strain hardening. Figure 4D shows a direct comparison of PS, $\mathrm{PS}_{0.95} \mathrm{~A}_{0.05}$, and $\mathrm{PS}_{0.91} \mathrm{~A}_{0.09}$ stretched at equivalent rates faster than the inverse Rouse time (see Table S1). The overlap of the linear viscoelastic envelopes for the three samples follows of course from the negligible effect of hydrogen bonding close to equilibrium. The high similarity of the strain hardening indicates that hydrogen bonding is not activated at nonequilibrium conditions. Note that the difference in steady state at high $\omega_{c} t$ could be related to the reproducibility of the experiments (see Figure S6) and different sample molar masses.

Mechanical Properties. While the lack of active hydrogen bonding in the melt allows for facile molding, shaping, and stretching of the polymers, interchain hydrogen bonding in the vitrified polymer is desirable to improve the specimen strength perpendicular to the stretch direction. Therefore, all three polymers were stretched to a Hencky strain of 3.5 above $T_{g}$ (using the experimental conditions from Figure 4D) and quenched by rapid cooling to room temperature. The presence of acid dimers was confirmed by ATR-FTIR spectroscopy (see Figure $3 \mathrm{D}$ ), which are comparable to spectra of the meltprocessed pellets (see Figure $3 \mathrm{C}$ ) with respect to ratio between carbonyl groups assigned to free acid and dimer. The IR spectra of the stretched, acid-containing samples feature an additional band at around $1650 \mathrm{~cm}^{-1}$. A shift in the carbonyl band to lower wavenumbers in the IR spectra of carbonylcontaining polymers typically indicates the formation of crystalline domains or preferred conformations of the structural units. However, typical shifts are on the order of $10-20 \mathrm{~cm}^{-1},{ }^{40,41}$ whereas the observed shift here is around 50 $\mathrm{cm}^{-1}$. To determine whether this is due to local formation of highly crystalline domains or something else entirely would require a more detailed analysis of the stretched samples, which lies outside the scope of this work.

Figure 5 compares the tensile test response for PS and $\mathrm{PS}_{0.91} \mathrm{~A}_{0.09}$. The tensile tests were performed with a strain rate of $0.001 \mathrm{~s}^{-1}$ at room temperature. In contrast to conventional PS with a critical strain at fracture usually less than $2 \%$, here, both samples can be pulled to a critical strain of more than $30 \%$. This is in agreement with the previous observation that PS became flexible when stretched faster than the inverse Rouse time during processing. ${ }^{2}$ In addition, strain softening is observed in both samples, while the yield stress increases with the hydrogen bonding content. Note that the reproducibility of tensile tests is relatively good (see Figure S9), so it is irrelevant to the yield stress difference. According to the Haward and Thackray model, ${ }^{42}$ a material's response can be described by two contributions: the secondary intermolecular interactions, which control the initial elastic response up to a yield point and the entanglement network response, which gives an entropic contribution at large strains. In our modified material, the range of the elastic response increased while the stress after the yield point follows the same slope for the modified and unmodified material. In terms of the Haward and Thackray model, therefore, the hydrogen bonding contributes to the range of intermolecular stress but not to the network stress. In addition, the Young's modulus, which is the initial slope of the stress-strain response, was found to be around $4 \mathrm{GPa}$ for both specimens. This is a typical order of magnitude for glassy polymers. $^{43}$

The effect of hydrogen bonding toward improving the bending stability was tested using a 3-point bending test. Figure 6A,C shows a flexible PS sample after irreversible bending. Multiple cracks in the filament appear in and around the bend. Figure $6 \mathrm{~B}, \mathrm{D}$ shows a flexible $\mathrm{PS}_{0.95} \mathrm{~A}_{0.05}$ bent to the same extent as the PS sample. Visual inspection reveals a less cracked sample.

The bending properties were quantitatively measured by investigating the stress-strain response, as presented in Figure $6 \mathrm{E}$. The bending modulus calculated from the initial slope is the same for all three samples, around $4 \mathrm{GPa}$, which is in agreement with the Young's modulus obtained from tensile 

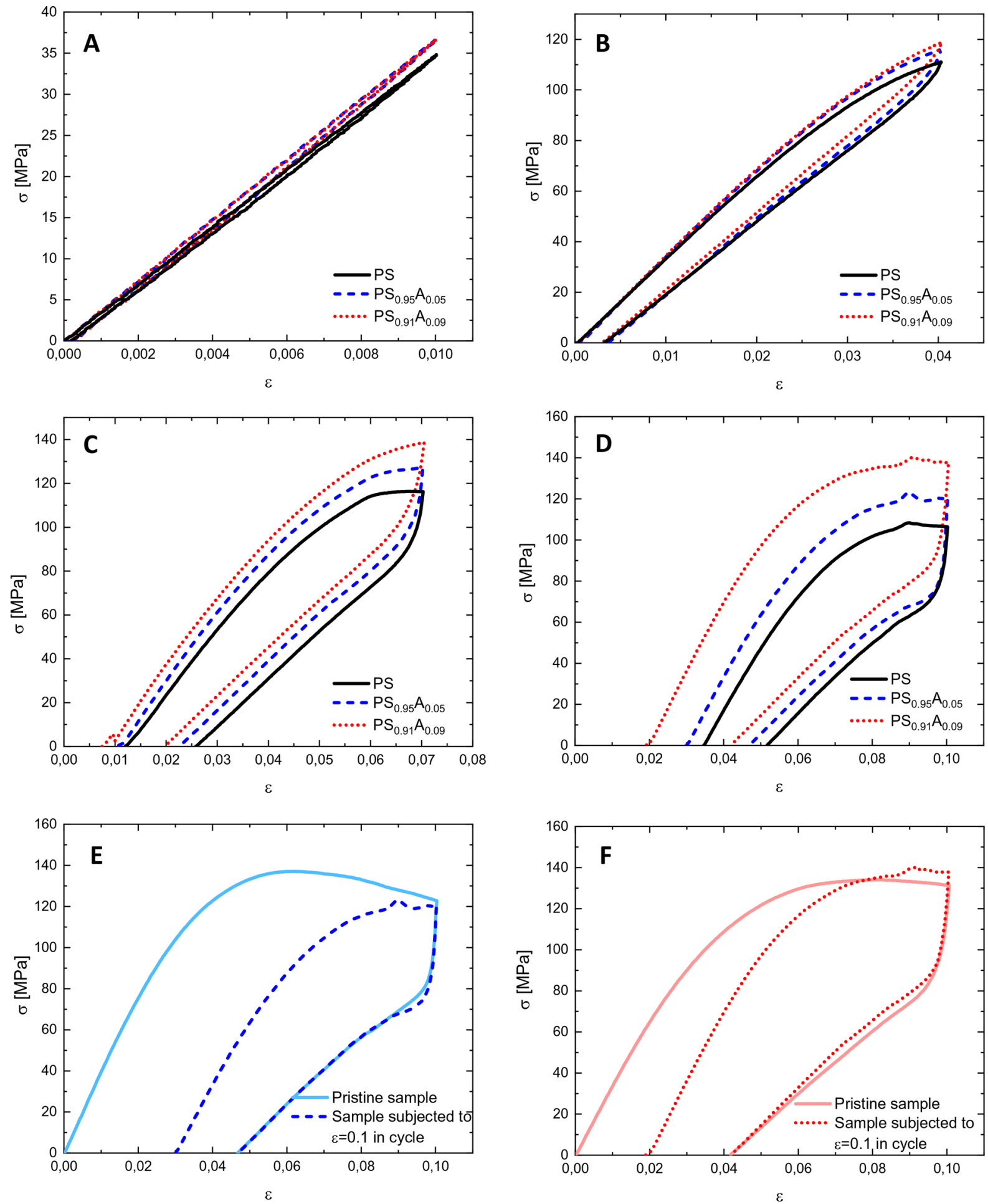

Figure 7. (A-D) Recovery after strain of flexible PS, $\mathrm{PS}_{0.95} \mathrm{~A}_{0.05}$ and $\mathrm{PS}_{0.91} \mathrm{~A}_{0.09}$ at $(\mathrm{A}) \varepsilon=0.01,(\mathrm{~B}) \varepsilon=0.04,(\mathrm{C}) \varepsilon=0.07$, and $(\mathrm{D}) \varepsilon=0.1$. $(\mathrm{E}, \mathrm{F})$ Measurements of acid-modified polystyrene samples measured as pristine samples and for samples previously subjected to strain measurements to a strain of 0.1. (E) $\mathrm{PS}_{0.95} \mathrm{~A}_{0.05}$ and $(\mathrm{F}) \mathrm{PS}_{0.91} \mathrm{~A}_{0.09}$. Tests are performed on a 3-point test setting at room temperature $(\mathrm{v}=0.005 \mathrm{~mm} / \mathrm{s})$.

testing. It is also important to point out that the strain corresponding to the maximum stress increases with the hydrogen bonding content, that is, the ductility of the material has increased. The average strain values at the corresponding maximum stress are listed in Table 2, where the uncertainty is the standard error calculated from three independent measurements of the same batch. The difference in strain is beyond experimental error, as seen in Figure S11.
In general, the brittleness of materials is expected to increase with the distance to glass-transition temperature. ${ }^{44,45}$ Ideally, these materials should be tested at a temperature with the same distance to $T_{\mathrm{g}}$. Thus, the specimens with acid groups should be tested above room temperature since their glass-transition temperatures are higher than that of polystyrene. However in this case, the opposite is true; the more ductile sample $\left(\mathrm{PS}_{0.91} \mathrm{~A}_{0.09}\right)$ is the one with the highest glass-transition 
temperature, which emphasizes that the observed effect is not due to the change in $T_{\mathrm{g}}$ but to the added hydrogen-bonding groups.

Figure $7 \mathrm{~A}-\mathrm{D}$ shows a cyclic bending measurement using the setting of 3-point bending. Each sample was first deformed to a strain of 0.01 . The deformation was then removed, leading to sample recovery, and the strain was measured for the same time as was used for the deformation. The procedure was then repeated with progressively increasing strain until ultimately a strain of 0.1 was applied. The stress-strain recovery response for these different samples is seen to be highly dependent on the applied deformation. Thus, at a strain of 0.01 , all three samples recover to their initial shape after deformation. Increasing the strain leads to a difference between deformation and recovery curves due to dissipation of energy and loss of shape. At high deformation (strain of 0.1, Figure 7D), samples with higher acid content and thereby hydrogen bonding capability show improved recovery.

To confirm this effect of hydrogen bonding and to exclude the influence from residual deformation, pristine samples of $\mathrm{PS}_{0.95} \mathrm{~A}_{0.05}$ and $\mathrm{PS}_{0.91} \mathrm{~A}_{0.09}$ were tested by immediately imposing a strain of 0.1 , followed by recording of the recovery path. As seen in Figure $7 \mathrm{E}, \mathrm{F}$, the recovery of pristine samples and gradually strained samples overlaps almost perfectly. The bending properties of these materials have a strain dependence, which is similar to Mullins effect as usually observed in elastic rubber materials. ${ }^{46,47}$

\section{SUMMARY AND CONCLUSIONS}

Acid-functional copolymers of styrene and 4-vinylbenzoic acid with acid fractions up to 0.16 are conveniently prepared by RAFT polymerization in bulk. As expected from the available literature data, the reactivity ratio of 4-vinylbenzoic acid is larger than that of styrene. However, since the reactive ratios are not highly different, block formation is suppressed at the studied styrene-rich copolymer compositions, although some compositional drift cannot be avoided.

Evidence of hydrogen bonding in the form of carboxylic acid dimers is found in the vitrified copolymers using IR spectroscopy, whereas linear viscoelastic and nonlinear extensional rheology confirm the absence of hydrogen bonding in the melts. The absence of hydrogen bonds allowed the preparation of flexible, anisotropic polymer specimens by stretching faster than the inverse Rouse time followed by rapid quenching to room temperature. The resulting specimens have increased yield stress and ductility as measured by tensile testing and 3-point bending experiments compared to flexible, anisotropic polystyrene without acid groups. This demonstrates how bulk properties can be modified by addition of a small amount of interchain hydrogen bonds.

\section{ASSOCIATED CONTENT}

\section{S Supporting Information}

The Supporting Information is available free of charge at https://pubs.acs.org/doi/10.1021/acs.macromol.9b01843.

Additional figures, materials, experimental procedures, and instrumentation (PDF)

\section{AUTHOR INFORMATION}

\section{Corresponding Authors}

*E-mail: pjma@kt.dtu.dk (J.M.).

*E-mail: qh@kt.dtu.dk (Q.H.).
ORCID

Wendi Wang: 0000-0003-3357-7685

Anne L. Skov: 0000-0003-1223-6638

Qian Huang: 0000-0001-8777-4241

Notes

The authors declare no competing financial interest.

\section{ACKNOWLEDGMENTS}

The authors would like to thank Prof. Ole Hassager from DTU Chemical Engineering for discussions and suggestions. Financial supports from European Union's Horizon 2020 Programme for Research and Innovation under the Marie Skłodowska-Curie grant agreement no. 765811 (DoDyNet) and the Independent Research Fund Denmark (DFF-400500112) are gratefully acknowledged.

\section{REFERENCES}

(1) Govaert, L. E.; van Melick, H. G. H.; Meijer, H. E. H. Temporary toughening of polystyrene through mechanical pre-conditioning. Polymer 2001, 42, 1271-1274.

(2) Huang, Q.; Madsen, J.; Yu, L.; Borger, A.; Johannsen, S. R.; Mortensen, K.; Hassager, O. Highly Anisotropic Glassy Polystyrenes Are Flexible. ACS Macro Lett. 2018, 7, 1126-1130.

(3) Meijer, H. E. H.; Govaert, L. E. Mechanical performance of polymer systems: The relation between structure and properties. Prog. Polym. Sci. 2005, 30, 915-938.

(4) Gardner, D. J.; Blumentritt, M.; Wang, L.; Yildirim, N. Adhesion theories in wood adhesive bonding: A critical review. Rev. Adhes. Adhes. 2014, 2, 127-172.

(5) Song, J.; Chen, C.; Zhu, S.; Zhu, M.; Dai, J.; Ray, U.; Li, Y.; Kuang, Y.; Li, Y.; Quispe, N.; Yao, Y.; Gong, A.; Leiste, U. H.; Bruck, H. A.; Zhu, J. Y.; Vellore, A.; Li, H.; Minus, M. L.; Jia, Z.; Martini, A.; $\mathrm{Li}, \mathrm{T}$.; Hu, L. Processing bulk natural wood into a high-performance structural material. Nature 2018, 554, 224-228.

(6) Brunsveld, L.; Folmer, B. J. B.; Meijer, E. W.; Sijbesma, R. P. Supramolecular polymers. Chem. Rev. 2001, 101, 4071-4098.

(7) Hackelbusch, S.; Rossow, T.; van Assenbergh, P.; Seiffert, S. Chain Dynamics in Supramolecular Polymer Networks. Macromolecules 2013, 46, 6273-6286.

(8) Lewis, C. L.; Stewart, K.; Anthamatten, M. The influence of hydrogen bonding side-groups on viscoelastic behavior of linear and network polymers. Macromolecules 2014, 47, 729-740.

(9) Choperena, A.; Painter, P. Hydrogen bonding in polymers: Effect of temperature on the $\mathrm{OH}$ stretching bands of poly(vinylphenol). Macromolecules 2009, 42, 6159-6165.

(10) Smith, A. E.; Xu, X.; McCormick, C. L. Stimuli-responsive amphiphilic (co)polymers via RAFT polymerization. Prog. Polym. Sci. 2010, 35, 45-93.

(11) Boyer, C.; Bulmus, V.; Liu, J.; Davis, T. P.; Stenzel, M. H.; Barner-kowollik, C. Well-defined protein-polymer conjugates via in situ RAFT polymerization. J. Am. Chem. Soc. 2007, 129, 7145-7154.

(12) Moad, G.; Rizzardo, E.; Thang, S. H. RAFT Polymerization and Some of its Applications. Chem. Asian J. 2013, 8, 1634-1644.

(13) Yang, Y.; Li, H.; Zhang, Y.; Wang, H.; Xu, L.; Zhao, H. Poly(pvinylbenzoic acid)-block-polystyrene Self-assembled Structures as Templates in the Synthesis of ZIF-8. Chem. Asian J. 2017, 12, 753758.

(14) Abreu, A. S.; Oliveira, M.; Rodrigues, P. V.; Moura, I.; Botelho, G.; Machado, A. V. Synthesis and characterization of polystyreneblock-poly(vinylbenzoic acid): a promising compound for manipulating photoresponsive properties at the nanoscale. J. Mater. Sci. 2015, 50, 2788-2796.

(15) Zaitsev, B. A.; Shtraikhman, G. A. Copolymerization of some psubstituted styrene and $\alpha$-methylstyrene derivatives with styrene and methylmethacrylate. Polym. Sci. U.S.S.R. 1968, 10, 511-520.

(16) Ourdani, S.; Amrani, F. Study of the compatibility of poly[(styrene)-co-(4-vinylbenzoic acid)] with poly[(ethyl methacry- 
late)-co-(4-vinylpyridine)] blends. Macromol. Chem. Phys. 2000, 201, 2458-2463.

(17) Prasath, R. A.; Margarit-Puri, K.; Klapper, M. Emulsifier-free emulsion polymerization of styrene with 4-vinylbenzoic acid: Kinetics and distribution of the carboxyl groups. J. Appl. Polym. Sci. 2007, 103, 2910-2919.

(18) Rasmussen, H. K.; Bejenariu, A. G.; Hassager, O.; Auhl, D. Experimental evaluation of the pure configurational stress assumption in the flow dynamics of entangled polymer melts. J. Rheol. 2010, 54, 1325-1336.

(19) Chiefari, J.; Chong, Y. K.; Ercole, F.; Krstina, J.; Jeffery, J.; Le, T. P. T.; Mayadunne, R. T. A.; Meijs, G. F.; Moad, C. L.; Moad, G.; Rizzardo, E.; Thang, S. H. Living Free-Radical Polymerization by Reversible Addition-Fragmentation Chain Transfer: The RAFT Process. Macromolecules 1998, 31, 5559-5562.

(20) Quirk, R. P.; Lee, B. Experimental Criteria for Living Polymerizations. Polym. Int. 1992, 27, 359-367.

(21) Altintas, O.; Riazi, K.; Lee, R.; Lin, C. Y.; Coote, M. L.; Wilhelm, M.; Barner-Kowollik, C. RAFT-based polystyrene and polyacrylate melts under thermal and mechanical stress. Macromolecules 2013, 46, 8079-8091.

(22) Yoshikawa, C.; Goto, A.; Fukuda, T. Reactions of polystyrene radicals in a monomer-free atom transfer radical polymerization system. E-Polym. 2002, 2, 1-12.

(23) Sarbu, T.; Lin, K. Y.; Ell, J.; Siegwart, D. J.; Spanswick, J.; Matyjaszewski, K. Polystyrene with designed molecular weight distribution by atom transfer radical coupling. Macromolecules 2004, 37, 3120-3127.

(24) Minoshima, W.; White, J. L.; Spruiell, J. E. Experimental investigation of the influence of molecular weight distribution on the rheological properties of polypropylene melts. Polym. Eng. Sci. 1980, 20, 1166-1176.

(25) Wingstrand, S. L.; Shen, B.; Kornfield, J. A.; Mortensen, K.; Parisi, D.; Vlassopoulos, D.; Hassager, O. Rheological Link between Polymer Melts with a High Molecular Weight Tail and Enhanced Formation of Shish-Kebabs. ACS Macro Lett. 2017, 6, 1268-1273.

(26) Sugimoto, M.; Masubuchi, Y.; Takimoto, J.; Koyama, K. Melt rheology of polypropylene containing small amounts of highmolecular-weight chain. 2. Uniaxial and biaxial extensional flow. Macromolecules 2001, 34, 6056-6063.

(27) Benvenuta-Tapia, J. J.; Tenorio-López, J. A.; Vivaldo-Lima, E. Estimation of Reactivity Ratios in the RAFT Copolymerization of Styrene and Glycidyl Methacrylate. Macromol. React. Eng. 2018, 12, 1800003.

(28) Mandal, B. M. Fundamentals of Polymerization; World Scientific Publishing, 2013, $388 \mathrm{ff}$.

(29) Fox, T. G. Influence of Diluent and of Copolymer Composition on the Glass Temperature of a Polymer System. Bull. Am. Phys. Soc. 1956, 1, 123.

(30) Ito, H.; Wilson, C. G.; Frechet, J. M. Positive/Negative Mid Uv Resists With High Thermal Stability. In Advances in Resist Technology and Processing IV; Bowden, M. J., Ed.; SPIE: 1987; 771, 24-31.

(31) Świtała-Żeliazkow, M. Thermal degradation of copolymers of styrene with dicarboxylic acids - II: Copolymers obtained by radical copolymerisation of styrene with maleic acid or fumaric acid. Polym. Degrad. Stab. 2006, 91, 1233-1239.

(32) Bershtein, V. A.; Yegorov, V. M.; Razgulyayeva, L. G.; Stepanov, V. A. The use of differential scanning calorimetry for evaluating the intermolecular reaction changes in glass-like polymers. Polym. Sci. U.S.S.R. 1978, 20, 2560-2568.

(33) Bershtein, V. A.; Razgulyayeva, L. G.; Gal'perin, V. M.; Yegorov, V. M.; Kolosova, T. O.; Lagunov, V. A.; Sinani, A. B. Molecular interaction and conformation of molecules in polystyrene and styrene-methacrylic acid copolymers. Polymer Science U.S.S.R. 1978, 20, 2118-2127.

(34) Nobile, M. R.; Cocchini, F. Predictions of linear viscoelastic properties for polydisperse entangled polymers. Rheol. Acta 2000, 39, $152-162$.
(35) Huang, C.-L.; Chen, Y.-C.; Hsiao, T.-J.; Tsai, J.-C.; Wang, C. Effect of tacticity on viscoelastic properties of polystyrene. Macromolecules 2011, 44, 6155-6161.

(36) Rizzardo, E.; Chen, M.; Chong, B.; Moad, G.; Skidmore, M.; Thang, S. H. RAFT polymerization: adding to the picture. Macromol. Symp. 2007, 248, 104-116.

(37) Tolstorozhev, G. B.; Bel'kov, M. V.; Skornyakov, I. V.; Bazyl, O. K.; Artyukhov, V. Y.; Mayer, G. V.; Shadyro, O. I.; Kuzovkov, P. V.; Brinkevich, S. D.; Samovich, S. N. Infrared Spectroscopy of Hydrogen Bonds in Benzoic Acid Derivatives. J. Appl. Spectrosc. 2014, 81, 109117.

(38) Huang, Q.; Mednova, O.; Rasmussen, H. K.; Alvarez, N. J.; Skov, A. L.; Almdal, K.; Hassager, O. Concentrated polymer solutions are different from melts: Role of entanglement molecular weight. Macromolecules 2013, 46, 5026-5035.

(39) Huang, Q.; Hengeller, L.; Alvarez, N. J.; Hassager, O. Bridging the Gap between Polymer Melts and Solutions in Extensional Rheology. Macromolecules 2015, 48, 4158-4163.

(40) Coleman, M. M.; Zarian, J. Fourier-transform infrared studies of polymer blends. II. Poly( $\epsilon$-caprolactone)-poly(vinyl chloride) system. J. Polym. Sci.: Polym. Phys. Ed. 1979, 17, 837-850.

(41) Jang, J.; Won, J. Crystallisation and phase behaviour of poly(butylene terephthalate)/polyarylate blends. Polymer 1998, 39, 4335-4342.

(42) Haward, R. N.; Thackray, G. The use of a mathematical model to describe isothermal stress-strain curves in glassy thermoplastics. Proc. R. Soc. London, Ser. A 1968, 302, 453-472.

(43) Gilmour, I. W.; Trainor, A.; Haward, R. N. Elastic moduli of glassy polymers at low strains. J. Appl. Polym. Sci. 1979, 23, 31293138.

(44) Van Melick, H. G. H.; Govaert, L. E.; Meijer, H. E. H. Prediction of brittle-to-ductile transitions in polystyrene. Polymer 2003, 44, 457-465.

(45) Matsushige, K.; Radcliffe, S. V.; Baer, E. The Pressure and Temperature Effects on Brittle-to-Ductile Transition in PS and PMMA. J. Appl. Polym. Sci. 1976, 20, 1853-1866.

(46) Govindjee, S.; Simo, J. C. Mullins effect and the strain amplitude dependence of the storage modulus. Int. J. Solids Struct. 1992, 29, 1737-1751.

(47) Diani, J.; Fayolle, B.; Gilormini, P. A review on the Mullins effect. Eur. Polym. J. 2009, 45, 601-612. 